\title{
Produção e caracterização físico-química de fermentado de umbu
}

\author{
Production and physicochemical characterization of fermented umbu
}

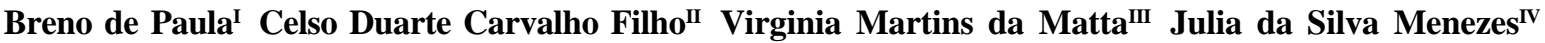 \\ Pâmela da Costa Lima ${ }^{\text {IV }}$ Claudia Oliveira Pinto ${ }^{\text {IV }}$ Lauro Eduardo Macedo Guedes Conceição $^{\text {IV }}$
}

\section{RESUMO}

O objetivo deste trabalho foi desenvolver um fermentado de umbu visando a agregar valor a esse fruto $e$ contribuir para a melhoria de renda das famílias do semiárido nordestino. A polpa utilizada nos experimentos foi submetida a análises físico-químicas e microbiológicas. Para a produção da bebida, a polpa foi diluída em água, sendo necessário realizar uma chaptalização com sacarose até atingir $20,5^{\circ} \mathrm{Brix}$. A levedura vínica comercial utilizada foi Saccharomyces cerevisiae. A fermentação foi conduzida a $18^{\circ} \mathrm{C}$ durante 18 dias $e$ posteriormente a bebida foi submetida a uma estabilização com auxílio de agentes de sedimentação, gelatina e bentonita, por 14 dias $a 1^{\circ} \mathrm{C}$. Após a estabilização, o fermentado de umbu foi filtrado em filtro prensa. O fermentado de umbu obtido apresentou teor alcoolico de $11,20^{\circ} \mathrm{GL}$. A bebida foi analisada quanto às suas características físico-químicas e todos os parâmetros estavam em conformidade com a legislação vigente.

Palavras-chave: Spondias tuberosa Arr. Cam., fermentação alcoolica, agregação de valor, fermentado de frutas, bebida alcoolica, legislação.

\section{ABSTRACT}

The objective of this study was to develop a fermented umbu drink aiming at adding value to this fruit and contribute for improving the families income in Brazil northeast semiarid region. The pulp used in the experiments was subjected to physico-chemical and microbiological analysis. For the production of liquor, the pulp was diluted with water, and needed a sugaring with sucrose up to $20.5^{\circ}$ Brix. A commercial Saccharomyces cerevisiae wine yeast was used. The fermentation was conducted at $18^{\circ} \mathrm{C}$ for 18 days and subsequently underwent a drink with the aid of stabilizing agents of sedimentation, gelatin and bentonite, for 14 days at $1^{\circ} \mathrm{C}$. After stabilizing the fermented umbu drink was subjected to filtered in filter press. The fermented alcoholic umbu drink showed an alcohol contents of $11.20^{\circ} \mathrm{GL}$. The drink was analyzed for their physicochemical characteristics and all parameters were in accordance with current legislation.

Key words: Spondias tuberosa Arr. Cam., alcoholic fermentation, adding value, fermented fruit, alcoholic beverage, legislation.

\section{INTRODUÇÃO}

O umbuzeiro é uma planta frutífera do gênero Spondias, nativa de regiões semi-áridas do Nordeste brasileiro. Pertencente à família das anacardiáceas, é uma árvore de pequeno porte, copa em forma de guardachuva, esparramada, tronco curto, galhos retorcidos e muito ramificados. É uma planta xerófila e caducifólia, por isso adaptada ao calor, aos solos pobres e de baixa densidade pluvial (MENDES, 1990).

A sua fruta é uma drupa, com diâmetro variando de 2 a $4 \mathrm{~cm}$, massa entre 10 e $20 \mathrm{~g}$, forma arredondada a ovalada, constituída por casca (22\%), polpa (68\%) e caroço (10\%). Possui superfície lisa com casca de cor amarelo-esverdeada e polpa brancoesverdeada, mole, suculenta, quase aquosa quando madura e sabor agridoce (LIMA et al., 2000). É conhecida como umbu, imbu ou ambu.

Instituto Federal de Educação, Ciência e Tecnologia da Bahia (IFBA), BR 367, Km 57,5, Bairro Fontana I, 45810-000, Porto Seguro, BA, Brasil. E-mail: brenoeal@gmail.com. Autor para correspondência.

"Faculdade de Farmácia, Universidade Federal da Bahia (UFBA), Salvador, BA, Brasil.

"IIEmbrapa Agroindústria de Alimentos, Rio de Janeiro, RJ, Brasil.

${ }^{\mathrm{IV}}$ Centro de Tecnologia SENAI-RJ Alimentos e Bebidas, Vassouras, RJ, Brasil. 
O umbu é uma fonte de renda para as famílias dos agricultores da região semi-árida do nordeste. No entanto, é uma fruta de período sazonal curto e de elevada perecibilidade. O extrativismo do umbu é a maneira mais tradicional de exploração, sendo os principais estados produtores Bahia, Pernambuco, Rio Grande do Norte, Piauí e Paraíba. A produção, em 2007 (IBGE, 2008), foi de 8.619 toneladas, com destaque para o sertão do estado da Bahia.

Em muitas comunidades rurais, o extrativismo do umbu é responsável por significativa parte da renda dos agricultores na época da safra. De acordo com FRAGA (2011), a venda do saco de umbu pesando $45 \mathrm{~kg}$ rende, em média, ao produtor e sua família R\$17,00. Segundo dados da Embrapa, 60kg da fruta, se processada e transformada em doce, suco ou geleia, pode elevar o rendimento para $\mathrm{R} \$ 135,00$ (MONTEIRO, 2003). Outra alternativa de produto que pode agregar valor ao fruto é a elaboração de uma bebida fermentada: através de cálculos estimados sem levar em consideração custos de produção, o mesmo saco de umbu pesando $45 \mathrm{~kg}$ produz, pelo processo utilizado no presente trabalho, aproximadamente $75 \mathrm{~L}$ de fermentado de umbu, que pode ser comercializado por $\mathrm{R} \$ 10,00$ a garrafa de um litro. De acordo com o Decreto $\mathrm{n}^{\circ}$ 6.871, de 04 de junho de 2009 do Ministério da Agricultura, Pecuária e do Abastecimento (MAPA), que regulamenta a Lei no 8.918 , de 14 de julho de 1994 , fermentado de fruta é a bebida com graduação alcoolica de quatro a quatorze por cento em volume, a vinte graus Celsius, obtida da fermentação alcoolica do mosto de fruta sã, fresca e madura (BRASIL, 2009). Vinho é a denominação reservada para o fermentado produzido por meio da fermentação da uva, sendo proibida sua utilização para produtos obtidos de outras matériasprimas, de acordo com a Lei no 7.678 (BRASIL, 1988).

Nos últimos anos, diversas frutas têm sido pesquisadas para produção de fermentados de frutas.

MÉLO et al. (2007) identificaram 17 espécies de leveduras presentes na polpa dos frutos do umbuzeiro, de um total de 54 isoladas. Das leveduras identificadas, nove foram utilizadas na fabricação artesanal de fermentado de umbu, sendo que as espécies Candida spadovensis, Candida valida, Candida tenuis-like e Candida florica-like foram as que resultaram em produtos com maior teor alcoolico $\left(10^{\circ} \mathrm{GL}\right)$. Em outro trabalho, MÉLO (2005) utilizou duas espécies de leveduras isoladas da polpa do umbu,

Kluyveroyces marxianus e Kloeckera japonica, e uma Saccharomyces cerevisiae comercial de panificação liofilizada da marca FERMIX e observou que a última produziu o fermentado com menor tempo e com menor concentração de açúcar residual.
O presente trabalho tem como objetivo o desenvolvimento de um fermentado de umbu utilizando técnicas industriais e insumos enológicos comerciais, empregados na produção de vinhos, visando a agregar valor a esse fruto e contribuir para a melhoria de renda das famílias do semiárido nordestino.

\section{MATERIAL E MÉTODOS}

A matéria-prima utilizada, polpa de umbu comercial pasteurizada, proveniente de um único lote de produção, foi diluída em água na proporção de 35:65. Em função do baixo teor de sólidos solúveis, principalmente após a diluição da polpa $\left(2,4^{\circ} \mathrm{Brix}\right)$, foi necessário realizar uma chaptalização no mosto, sendo adicionados $13,9 \mathrm{~kg}$ de sacarose comercial em $61,1 \mathrm{~L}$ da polpa diluída a $2,4^{\circ} \mathrm{Brix}$, calculado através do quadrado de Pearson. Foram obtidos $75 \mathrm{~L}$ de mosto com teor de sólidos solúveis de $20,5^{\circ}$ Brix, que foi sulfitado utilizando $3,75 \mathrm{~g}$ de Antioxin ${ }^{\circledR} \mathrm{W}$, que é composto de pirossulfito de potássio $\left(\mathrm{K}_{2} \mathrm{~S}_{2} \mathrm{O}_{5}\right)$ combinado com ácido ascórbico $\left(\mathrm{C}_{6} \mathrm{H}_{8} \mathrm{O}_{6}\right)$ e o pH foi corrigido para 3,7 com adição de carbonato de cálcio $\left(\mathrm{CaCO}_{3}\right)$.

O mosto foi submetido a um tratamento enzimático visando hidrolisar a pectina para aumentar o rendimento na fermentação, e enriquecido com $30 \mathrm{~g}$ de nutriente para fermentação Fermoplus ${ }^{\circledR}$ Millenium, a base de compostos nitrogenados necessários para o desenvolvimento das leveduras. Foram utilizadas duas enzimas pectinolíticas comerciais, a Endozym ${ }^{\circledR}$ Active e a Endozym ${ }^{\circledR}$ Éclair, ambas com baixa atividade de pectinesterase, visando reduzir a liberação de metanol. Foram utilizados $20 \mathrm{ppm}$ de cada enzima a $25^{\circ} \mathrm{C}$ por $40 \mathrm{~min}$.

O pré-inóculo foi preparado com a levedura vínica comercial Fermol ${ }^{\circledR}$ Millenium (multi-estirpes de Sacharomyces cerevisiae) com concentração inicial de $20 \mathrm{~g}$ de levedura para $100 \mathrm{~kg}$ de mosto, e mantida a $35^{\circ} \mathrm{C} /$ $20 \mathrm{~min}$. A propagação foi realizada por meio de quatro dobras de volume com adição do mosto, sendo a primeira após 20 minutos com a adição de $165 \mathrm{~g}$ de mosto nos $165 \mathrm{~g}$ de preparado da levedura. A segunda, a terceira e a quarta dobra foram realizadas em intervalos de uma hora com adição de $330 \mathrm{~g}, 660 \mathrm{~g}$ e $1.320 \mathrm{~g}$ de mosto, respectivamente.

A fermentação foi conduzida em dois barris de aço inoxidável de 50L, adaptado com batoque hidráulico para eliminar o gás carbônico formado durante a fermentação sem permitir a entrada de oxigênio nos reatores. Os barris foram acondicionados em uma câmara de refrigeração a $18^{\circ} \mathrm{C}$ por um período de 18 dias. A fermentação foi monitorada pela análise diária do grau alcoolico real $\left({ }^{\circ} \mathrm{GL}\right)$, que se baseia na separação do álcool por destilação da amostra no 
aparelho de Kjeldahl para posterior quantificação da densidade relativa do destilado a $20^{\circ} \mathrm{C}$, utilizando picnômetro, em que o valor encontrado é lido numa tabela com valores de densidade relativa a $20^{\circ} \mathrm{C}$, correlacionados com valores de grau alcoolico real (BRASIL, 2005). Também foram realizadas diariamente análises do teor de sólidos solúveis ( ${ }^{\circ}$ Brix) utilizando refratômetro, da acidez total titulável (meq L $\mathrm{L}^{-1}$ ) e do $\mathrm{pH}$ em potenciômetro, conforme as normas analíticas do Instituto Adolfo Lutz (2008). As amostras foram retiradas por meio de um sistema composto de uma seringa acoplada a um reservatório autoclavável com uma mangueira de silicone. Ao final da fermentação, foi realizada uma trasfega, separando os depósitos formados pela sedimentação das fibras da polpa, coloides e massa celular oriunda das leveduras que podem alterar o fermentado, dando origem a substâncias de odor desagradável, como ácido sulfídrico $\left(\mathrm{H}_{2} \mathrm{~S}\right)$ e mercaptanas. Em seguida, foi realizada uma nova sulfitação com adição de $2,5 \mathrm{~g}$ do Antioxin $^{\circledR}$ $\mathrm{W}$ nos $50 \mathrm{~L}$ restantes do fermentado.

Para acelerar a etapa de estabilização, foram utilizados dois agentes de sedimentação, o Gelsol ${ }^{\circledR}$ que é uma gelatina líquida concentrada $(5 \mathrm{~g})$ e o Bentogran ${ }^{\circledR}$ que é uma bentonita granular ( $35 \mathrm{~g})$, sendo conduzida a $1{ }^{\circ} \mathrm{C}$ por 14 dias. Após esta etapa, foi realizada uma nova trasfega e foi utilizada a filtração convencional em filtro prensa com placas de celulose com poros de $1 \mu \mathrm{m}$ e área de filtração de $0,44 \mathrm{~m}^{2}$ para remoção das partículas coloidais.

A polpa foi caracterizada por meio de análises físico-químicas de umidade em estufa a $105^{\circ} \mathrm{C}$, resíduo mineral fixo em mufla a $550^{\circ} \mathrm{C}, \mathrm{pH}$ em potenciômetro, sólidos solúveis totais $\left({ }^{\circ} \mathrm{Brix}\right)$ utilizando refratômetro, acidez total por titulação (expressa em ácido cítrico), ácido ascórbico por titulação, proteínas pelo método de Kjeldahl, lipídeos pelo método de Soxhlet e pectina por gravimetria, conforme as normas analíticas do Instituto Adolfo Lutz (2008). As determinações de açúcares redutores e açúcares totais foram realizadas conforme o método espectrofotométrico do ácido 3,5 dinitrosalicílico (DNS), em que o ácido em meio alcalino oxida a carbonila do açúcar redutor, gerando complexos de coloração alaranjada que são quantificados pelo espectrofotômetro a 540nm (MILLER, 1959). Para analisar os açúcares totais, a amostra foi submetida a uma hidrolise prévia com ácido clorídrico $(\mathrm{HCl})$. Os açúcares não redutores foram determinados por diferença. A caracterização microbiológica foi realizada pela contagem de bactérias totais, fungos filamentosos e leveduras, coliformes a $35^{\circ} \mathrm{C}$, Escherichia coli e Salmonella sp (BRASIL, 2003).
O fermentado de umbu foi analisado quanto às suas características físico-químicas, de acordo com a Instrução Normativa no 24, de 8 de Setembro de 2005, que regulamenta o Manual Operacional de Bebidas e Vinagre (BRASIL, 2005). Foram analisados o grau alcoolico real (picnômetro), o pH (potenciômetro), a acidez total titulável, a acidez volátil (titulação), acidez fixa por cálculo, o extrato seco total (densímetro), o extrato seco reduzido por cálculo, as cinzas (gravimetria) e açúcares totais pelo método DNS (MILLER, 1959).

\section{RESULTADOS E DISCUSSÃO}

Os resultados das análises microbiológicas da polpa de umbu (contagem de bactérias totais $\left(1,3 \times 10^{2} \mathrm{UFC} \mathrm{g}^{-1}\right)$, fungos filamentosos e leveduras $\left(<1,0 \times 10^{2} \mathrm{UFC} \mathrm{g}^{-1}\right)$, coliformes a $35^{\circ} \mathrm{C}\left(1,0 \times 10^{1} \mathrm{UFC} \mathrm{g}^{-1}\right)$, Escherichia coli $\left(<1,0 \times 10^{1} \mathrm{UFC} \mathrm{g}^{-1}\right)$ e Salmonella sp (Ausente em 25g) demonstraram que a polpa apresentava condições higiênico sanitárias satisfatórias (BRASIL, 2001). Na tabela 1, é apresentada sua composição química e $\mathrm{pH}$.

$\mathrm{O} \mathrm{pH}$ apresentou um pequeno aumento durante os dois primeiros dias de fermentação e em seguida uma pequena queda até atingir um valor próximo de 3,10 no final do processo. Alguns aspectos como crescimento bacteriano, solubilidade de proteínas, efeito do dióxido de enxofre, efetividade da bentonita e reações de escurecimento, estão diretamente relacionados ao $\mathrm{pH}$. Limites de $\mathrm{pH}$ entre 3 e 4 aumentam a resistência à contaminação bacteriana (AQUARONE et al., 2001). A curva da acidez total apresentou aumento gradativo durante a fermentação e está relacionada à diminuição do pH (Figura 1).

Tabela 1 - Caracterização físico-química da polpa de umbu.

\begin{tabular}{ll}
\hline Determinações & Resultados \\
\hline $\mathrm{pH}$ & $2,47 \pm 0,00$ \\
Sólidos solúveis ( ${ }^{\circ}$ Brix) & $6,47 \pm 0,15$ \\
Acidez em ác. cítrico (g 100g-1) & $1,38 \pm 0,02$ \\
Ratio ('Brix/acidez) & 4,59 \\
Umidade (\%) & $89,48 \pm 0,06$ \\
Proténas (\%) & $0,44 \pm 0,01$ \\
Lipídeos (\%) & $0,39 \pm 0,01$ \\
Açúcares redutores (\%) & $1,92 \pm 0,14$ \\
Açúcares não redutores (\%) & 0,54 \\
Açúcares totais (\%) & $2,46 \pm 0,19$ \\
Pectina (\%) & $1,10 \pm 0,02$ \\
Ácido ascórbico (mg/100g) & $24,97 \pm 0,01$ \\
Rezíduo mineral fixo (\%) & $0,41 \pm 0,01$ \\
\hline
\end{tabular}


A figura 2 representa a cinética de fermentação, demonstrando o consumo do substrato (açúcares) e a formação do produto (etanol), em função do tempo de fermentação, na qual é possível observar a redução gradual do teor de sólidos solúveis durante todo o período de fermentação, que foi de 18 dias.

Assim como observado nas curvas de $\mathrm{pH}$, acidez total e sólidos solúveis, a formação de etanol foi lenta e gradual durante os 18 dias de fermentação. Esse fato está relacionado à principal fonte de açúcar utilizada pela levedura e principalmente à temperatura utilizada no processo $\left(18^{\circ} \mathrm{C}\right)$. Como o teor de sólidos solúveis da polpa diluída em água foi $2,4^{\circ}$ Brix, a principal fonte de substrato para a levedura foi a sacarose. Para consumir a sacarose, a Saccharomyces cerevisiae precisa hidrolisá-la, transformando-a em glicose e frutose antes de ser metabolizada a etanol. Esse processo de hidrólise da sacarose necessita de um tempo maior quando a fermentação é conduzida a baixas temperaturas, pois a velocidade do metabolismo da levedura é menor.

A combinação de um mosto com alto teor de sacarose com a utilização de baixas temperaturas de fermentação resulta numa bebida com baixos teores de açúcares residuais, pois, em baixas temperaturas, o efeito tóxico do etanol é menor e a fermentação pode prolongarse, e baixos teores de metabólitos indesejáveis, como aldeídos, cetonas, ésteres, alcoois superiores e ácidos voláteis. Na tabela 2, é mostrada a composição química e $\mathrm{pH}$ do fermentado obtido e os limites estabelecidos pela legislação vigente. $\mathrm{O}$ teor alcoolico, acidez total $\mathrm{e}$ acidez volátil estão dentro dos limites estabelecidos pela legislação vigente no Brasil para fermentados de frutas (BRASIL, 2005; BRASIL, 2008).
A acidez total do fermentado de umbu, próxima do limite mínimo estabelecido pela legislação vigente (BRASIL, 2005), deve-se à baixa formação de ácidos voláteis, o que é um fator positivo, pois esses compostos, quando presentes em grande quantidade, desenvolvem sabor desagradável de vinagre. Já a acidez fixa ficou acima do mínimo permitido, o que era esperado devido à presença de ácidos orgânicos no umbu, como o ácido cítrico e o ascórbico, além dos produzidos durante a fermentação.

A Legislação não estabelece limites para $\mathrm{pH}$, extrato seco e cinzas. Entretanto, segundo ASQUIERI et al. (2004), um pH relativamente baixo, como o obtido no presente trabalho $(3,10)$, confere características de frescor à bebida.

O extrato seco pode variar em função das etapas de clarificação realizadas (tratamento enzimático, uso de agentes de sedimentação e filtração) desde a preparação do mosto até o envase do fermentado. Segundo AQUARONE et al. (1983), o extrato seco reduzido determina o corpo do vinho; quando o seu valor está abaixo de $20 \mathrm{~g} \mathrm{~L}^{-1}$ é considerado leve ou doce e acima de $25 \mathrm{~g} \mathrm{~L}^{-1}$, é considerado encorpado.

O extrato seco total, o extrato seco reduzido e o teor de cinzas do fermentado obtido no presente trabalho ficaram entre os teores reportados na literatura para outros fermentados de frutas. Por exemplo, no fermentado de jaca, ASQUIERI et al. (2008) detectaram $96,80 \mathrm{~g} \mathrm{~L}^{-1}$ de extrato seco total e $89,52 \mathrm{~g} \mathrm{~L}^{-1}$ de extrato seco reduzido. Em fermentado de kiwi, PAZ et al. (2007) detectaram $21,89 \mathrm{~g} \mathrm{~L}^{-1}$ de extrato seco total, $19,89 \mathrm{~g} \mathrm{~L}^{-1}$ de extrato seco reduzido e $3,07 \mathrm{~g} \mathrm{~L}^{-1}$ de cinzas e, em fermentado de acerola, os teores de cinzas foram $0,40 \mathrm{~g} \mathrm{~L}^{-1}$ (SANTOS et al., 2005). Segundo RIZZON \& MIELE

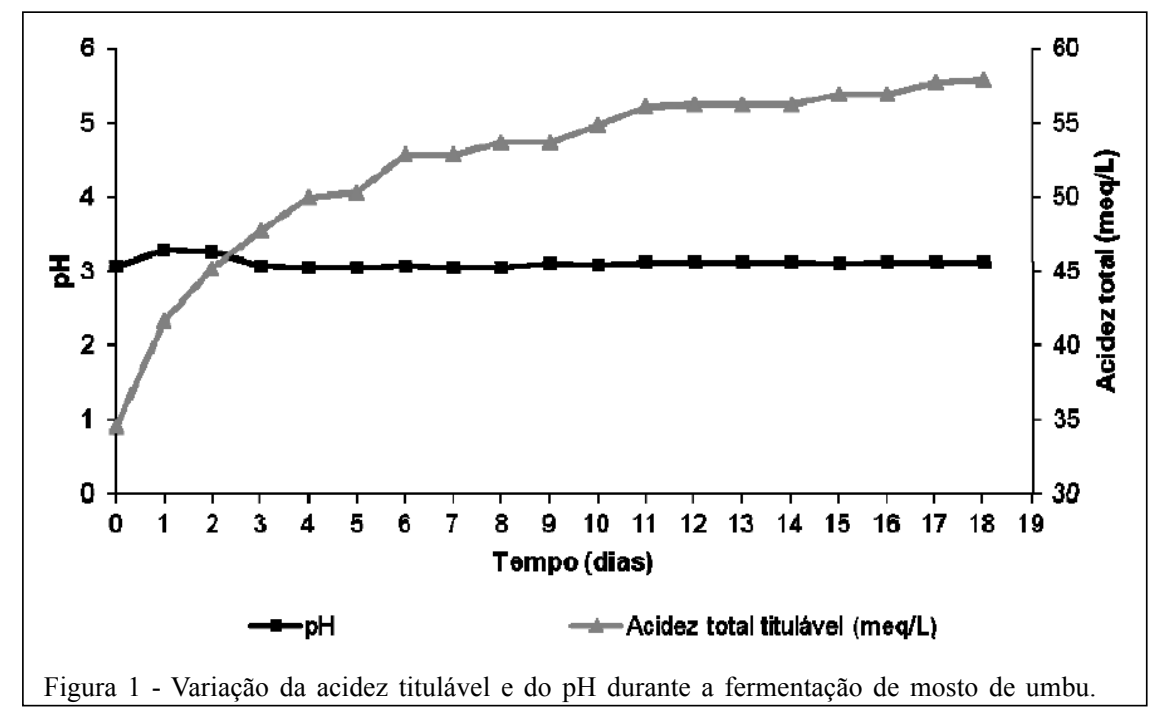

Ciência Rural, v.42, n.9, set, 2012. 


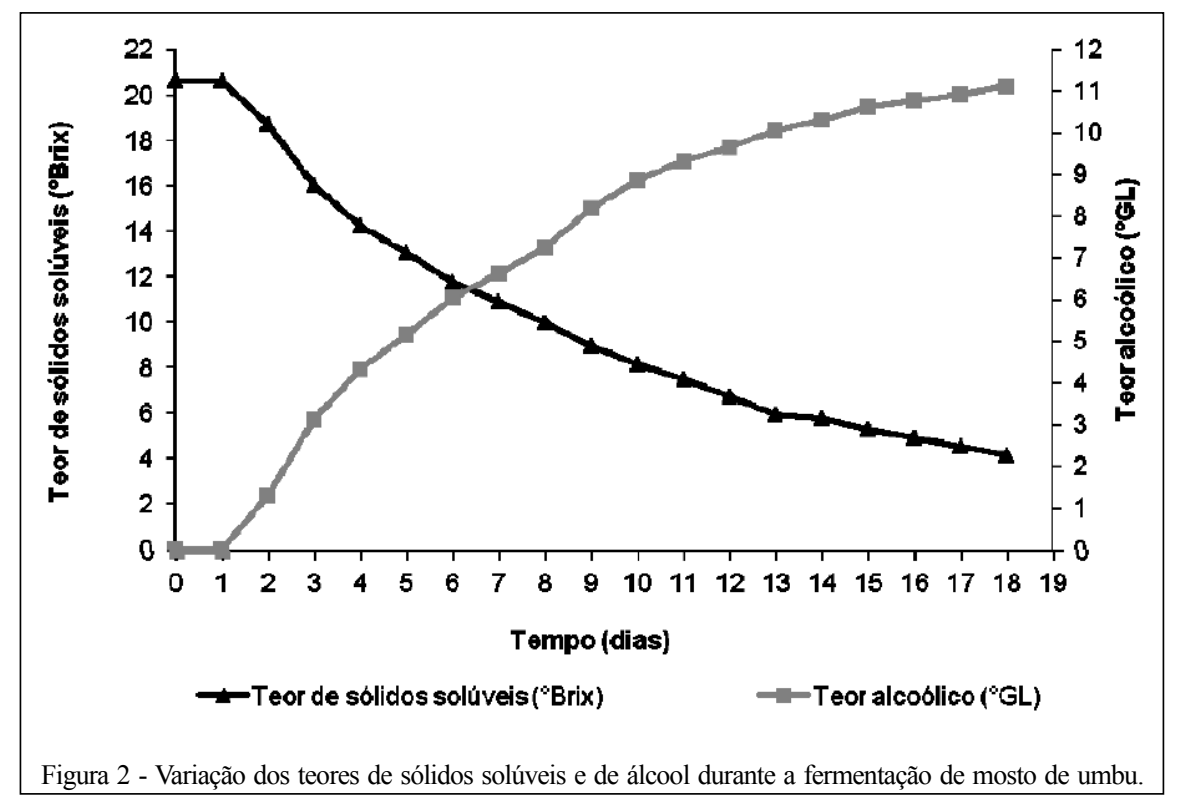

(2002), as cinzas, geralmente, correspondem a aproximadamente $10 \%$ do extrato seco reduzido em vinhos. A variação nos teores de cinzas, segundo NETO et al. (2006), são decorrentes, provavelmente, de má fermentação ou da presença de minerais estranhos à fruta.

O elevado teor de glicídios totais $\left(22,36 \mathrm{~g} \mathrm{~L}^{-1}\right)$ verificado no fermentado de umbu indica que ele pode ser comparado a um vinho branco de mesa do tipo suave e foi bem superior aos teores reportados pelos autores citados acima nos fermentados de kiwi $\left(3,0 \mathrm{~g} \mathrm{~L}^{-1}\right)$ e de acerola $\left(11,48 \mathrm{~g} \mathrm{~L}^{-1}\right)$.

\section{CONCLUSÃO}

A utilização do umbu para produção de uma bebida fermentada é uma alternativa tecnologicamente viável, pois os resultados obtidos em escala semiindustrial, comprovaram que é possível produzir um fermentado com características físico-químicas adequadas à Portaria no 64, de 23 de abril de 2008, e que poderia ser classificado do tipo suave. A produção de fermentado de umbu pode representar um incremento na renda das famílias do sertão nordestino que sobrevivem do extrativismo do umbu.

Tabela 2 - Caracterização físico-química do fermentado de umbu e seus respectivos limites legais.

\begin{tabular}{llc}
\hline Parâmetros & Resultados & Portaria $\mathrm{n}^{\mathrm{o}}$ 64 (BRASIL, 2008)* \\
\hline Grau alcoolico $\left(\% \mathrm{v} / \mathrm{v} \mathrm{a} 20^{\circ} \mathrm{C}\right)$ & $11,2 \pm 0,00$ & $\geq 4,0 \mathrm{e} \leq 14,0$ \\
Densidade relativa $\left(\mathrm{g} \mathrm{mL}^{-1} \mathrm{a} 20^{\circ} \mathrm{C}\right)$ & $1,0026 \pm 0,00$ & - \\
Acidez total $\left(\mathrm{meq} \mathrm{L}^{-1}\right)$ & $50,07 \pm 0,57$ & $\geq 50,0 \mathrm{e} \leq 130,0$ \\
Acidez fixa $\left(\mathrm{meq} \mathrm{L}^{-1}\right)$ & 42,8 & $\leq 20,00$ \\
Acidez volátil $\left(\mathrm{meq} \mathrm{L}^{-1}\right)$ & $7,27 \pm 1,08$ & $\geq 7,00$ \\
Extrato seco reduzido $\left(\mathrm{g} \mathrm{L}^{-1}\right)$ & 23,50 & - \\
Extrato seco total $\left(\mathrm{g} \mathrm{L}^{-1}\right)$ & 44,90 & - \\
Cinzas $(\%)$ & $2,36 \pm 0,07$ & - \\
Glicídios totais $\left(\mathrm{g} \mathrm{L}^{-1}\right)$ & $22,36 \pm 0,92$ & - \\
Glicídios redutores $\left(\mathrm{g} \mathrm{L}^{-1}\right)$ & $22,00 \pm 1,12$ & \\
\hline
\end{tabular}

*Os limites utilizados nesta tabela foram extraídos da Portaria n.64, de 23 de abril de 2008, que aprova o regulamento técnico para a fixação dos padrões de identidade e qualidade para os fermentados de frutas.

Ciência Rural, v.42, n.9, set, 2012. 


\section{AGRADECIMENTOS}

Ao Programa de Pós-graduação em Ciência de Alimentos da Universidade Federal da Bahia (UFBA), ao Centro de Tecnologia SENAI-RJ Alimentos e Bebidas e à Embrapa Agroindústria de Alimentos, por todo apoio para a execução dos experimentos, e à AEB Bioquímica Latino Americana por ter doado todos os insumos enológicos utilizados neste trabalho.

\section{REFERÊNCIAS}

AQUARONE, E. et al. Biotecnologia na produção de alimentos. São Paulo: Edgard Blücher, 2001. V.4, Série Biotecnologia Industrial. p.523.

ASQUIERI, E.R. et al. Vino de jabuticaba (Myrciaria cauliflora Berg): estudio de las características físico-químicas y sensoriales de los vinos tinto seco y dulce, fabricados com la fruta integral. Alimentaria, n.355, p.111-122, 2004

ASQUIERI, E.R. et al. Fermentado de jaca: estudo das características físico-químicas e sensoriais. Ciência e Tecnologia de Alimentos, v.28, n.4, p.881-887, 2008. Disponível em: <http: /dx.doi.org/10.1590/S0101-20612008000400018>. Acesso em 15 maio, 2012. doi: 10.1590/S0101-20612008000400018.

BRASIL. Decreto n.6871 de 4 de junho de 2009. Regulamenta a lei n.8918 de 14 de julho de 1994, que dispõe sobre a padronização, a classificação, o registro, a inspeção, a padronização e a fiscalização de bebidas. Diário Oficial da República Federativa do Brasil, Brasília, p.20, 5 de jun. 2009

BRASIL. Instrução normativa n.24 de 8 de Setembro de 2005 . Aprova o manual operacional de bebidas e vinagres. Brasília: Ministério da Agricultura, Pecuária e Abastecimento, 2005.

BRASIL. Instrução normativa n.62, de 26 de agosto de 2003. Oficializa os métodos analíticos oficiais para análises microbiológicas para controle de produtos de origem animal e água. Brasília: Ministério da Agricultura, Pecuária e Abastecimento, 2003.

BRASIL. Lei n.7678 de 08 de outubro de 1988. Dispõe sobre a produção, circulação e comercialização do vinho e derivados da uva e do vinho, e dá outras providências. Brasília: Ministério da Agricultura e de Abastecimento, 1988.

BRASIL. Portaria n. 64 de 23 de abril de 2008. Aprovam os regulamentos técnicos para a fixação dos padrões de identidade e qualidade para as bebidas alcoólicas fermentadas: fermentado de fruta, sidra, hidromel, fermentado de cana, fermentado de fruta licoroso, fermentado de fruta composto e saquê. Brasília: Ministério da Agricultura, Pecuária e Abastecimento, 2008

BRASIL. Resolução RDC n.12, de 02 de janeiro de 2001. Aprova o regulamento técnico sobre padrões microbiológicos para alimentos. Brasília: Ministério da Saúde, 2001.

FRAGA, A. Vinho de umbu é a alternativa para os produtores do semiárido baiano. Jornal A Tarde, Bahia, 28 fev. 2011. Caderno de Economia, Seção de Agronegócios, p.B8.
IBGE. Diretoria de Pesquisas, Coordenação de Agropecuária. Produção da extração vegetal e da silvicultura 2006-2007. Rio de Janeiro, 2008.

INSTITUTO ADOLFO LUTZ. Normas analíticas do Instituto Adolfo Lutz: métodos químicos e físicos para análise de alimentos. 4.ed. São Paulo, 2008. 1.020p.

LIMA, L.F.N. et al. Umbu (Spondias tuberosa Arr. Cam.). Jaboticabal: Funep, 2000. p.29.

MENDES, B.V. Umbuzeiro (Spondias tuberosa Arr. Cam.): importante fruteira do semi-árido. Mossoró: ESAM, 1990. 63p. (ESAM. Coleção Mossorense, série C, v.564).

MÉLO, D.L.F.M. et al. Identification of yeasts isolated from the pulp in nature and the production of homemade Umbu wine. Brazilian Archives of Biology and Technology, v.50, n.5, p.887-892, 2007. Disponível em: <http://dx.doi.org/ 10.1590/S1516-89132007000500017>. Acesso em: 15 maio, 2012. doi: 10.1590/S1516-89132007000500017.

MÉLO, D.L.F.M. Potencial biotecnológico do umbu: perspectivas para o semi-árido. 2005. 82f. Dissertação (Mestrado em Desenvolvimento e Meio Ambiente) Universidade Federal de Sergipe, SE.

MILLER, G.L. Use of dinitrosalicilic acid reagent for determination of reducing sugar. Analytical Chemistry, v.31, p.426-428, 1959. Disponível em: <http://pubs.acs.org/doi/abs/ 10.1021/ac60147a030>. Acesso em: 15 maio, 2012. doi: $10.1021 / \mathrm{ac} 60147 \mathrm{a} 030$.

MONTEIRO, G.F. Embrapa: balanço social 2002. Brasília: Assessoria de Comunicação Social, 2003. 61p.

NETO, A.B.T. et al. Cinética e caracterização físico-química do fermentado do pseudofruto do caju (Anacardium occidentale L.). Química Nova, v.29, p.489-492, 2006. Disponível em: <http:/ /dx.doi.org/10.1590/S0100-40422006000300015>. Acesso em: 15 maio, 2012. doi: 10.1590/S0100-40422006000300015.

PAZ, M.F. et al. Produção e caracterização do fermentado alcoolico de Actinidia deliciosa variedade bruno produzido em Santa Catarina. In: SIMPÓSIO NACIONAL DE BIOPROCESSOS, 16., 2007, Curitiba, PR. Anais SINAFERM. Curitiba, 2007. CD-Rom. V.1, p.PFE0088.

RIZZON, L.A.; MIELE, A. Avaliação da cv. cabernet sauvignon para elaboração de vinho tinto. Ciência e Tecnologia de Alimentos, v.22, n.2, p.192-198, 2002. Disponível em: <http://dx.doi.org/ 10.1590/S0101-20612002000200015>. Acesso em: 15 maio, 2012. doi: $10.1590 / \mathrm{S} 0101-20612002000200015$.

SANTOS, S.C. et al. Elaboração e análise sensorial do fermentado de acerola (Malpighia punicifolia L.). Brazilian Journal of Food Technology, Edição Especial, V SIPAL, p.4750, 2005. Disponível em: <http://bjft.ital.sp.gov.br/artigos// brazilianjournal/ed_especial/09.pdf>. Acesso em: 15 maio, 2012. 